\section{(A) Check for updates}

Cite this: Dalton Trans., 2019, 48, 11070

Received 30th April 2019, Accepted 30th May 2019

DOI: $10.1039 / \mathrm{c} 9 \mathrm{dt} 01814 \mathrm{j}$ rsc.li/dalton

\title{
Resolution of minor size differences in a family of heteroleptic coordination cages by trapped ion mobility ESI-MS†
}

\author{
Kristina E. Ebbert, Laura Schneider, André Platzek, Christoph Drechsler, Bin Chen, \\ Robin Rudolf and Guido H. Clever (D)*
}

\begin{abstract}
We report a complex system of heteroleptic coordination cages based on the combination of four bismonodentate ligands whose backbones only slightly differ in shape and length. cis- $\left[\mathrm{Pd}_{2} \mathrm{~L}_{2} \mathrm{~L}_{2}{ }_{2}\right]$ assemblies cleanly form after addition of $\mathrm{Pd}^{\prime \prime}$ cations to a 1:1 mixture of two shape-complementary ligands, each. When three or even all four ligands are used in combination, the unambiguous discrimination of all individual species in the product mixture becomes difficult by conventional NMR spectroscopic and mass spectrometric methods. Due to steric constraints, the system is restricted to the formation of ten different coordination cages in total, two of which are isomeric. We show that high-resolution trapped ion mobility mass spectrometry (TIMS) allows the clear differentiation of all ten species. Observed size trends could be readily reproduced by the calculation of theoretical values for collisional cross sections (CCS) from geometry-optimized models.
\end{abstract}

\section{Introduction}

Metal-mediated self-assembly of organic building blocks into larger supramolecules has yielded a plethora of structures over the last decades. ${ }^{1}$ Amongst these, coordination cages take a special role due to their guest recognition capabilities and potential to serve as nanoscopic reaction containers. ${ }^{2}$ Most reported examples have usually been based on one type of organic ligand, each, thus reducing synthetic effort, avoiding the formation of complicated reaction mixtures and simplifying analytical characterization. While this approach has produced a large number of systems with unique structures and functions, for example lantern-shaped, tetrahedral, octahedral, cubic cages and large spheres, ${ }^{3}$ the restriction to a single ligand component puts a limit on the achievable architectural design and functionality. We and others have therefore recently begun to invest effort in the rational design of multi-ligand heteroleptic coordination cages that form selectively from more than one kind of ligand - mostly under thermodynamic control - without generating statistical mixtures. ${ }^{4}$ While some of our recently reported approaches make use of donor-site engineering to achieve the formation of heteroleptic assemblies, ${ }^{5}$ the method forming the basis for the herein reported findings

Fakultät für Chemie und Chemische Biologie, TU Dortmund, Otto-Hahn Straße 6, 44227 Dortmund, Germany. E-mail: guido.clever@tu-dortmund.de

$\dagger$ Electronic supplementary information (ESI) available. See DOI: 10.1039/ c9dt01814j makes use of the size and shape complementarity of pairs of bis-monodentate ligands to selectively form a series of cisconfigured $\left[\mathrm{Pd}_{2} \mathrm{~L}_{2} \mathrm{~L}_{2}^{\prime}\right]$ cages with a bent appearance (Fig. 1). ${ }^{4 a, 6}$

2D NMR spectroscopic methods and single crystal diffraction are key methods for the structural characterization of pure samples of such heteroleptic species. However, these techniques show limitations when complex mixtures of species have to be examined. While diffusion ordered (DOSY) NMR spectroscopy is a powerful tool for the discrimination of individual components in a complex mixture, it becomes difficult to deliver unambiguous answers when larger objects show only small size differences and NMR signals of the separate species overlap heavily. ${ }^{7}$ Since increasing the complexity of supramolecular multi-component mixtures is common practice in the field of systems chemistry, powerful analytical techniques are required to keep track of such a system's composition. Chromatographic methods are often not suited for metallosupramolecular assemblies due to stability issues on the stationary phases. High resolution mass spectrometric analysis has developed into a powerful tool in supramolecular chemistry but cannot readily discriminate between isomeric/ isobaric species (except for special cases allowing MSMS fragmentation pattern analysis). ${ }^{8}$ Furthermore, standard MS methods do not deliver information related to the spatial dimensions of the analytes.

Recently, ion mobility spectrometry (IMS), usually coupled with high-resolution mass spectrometry, is gradually turning into a popular addition to the structural analysis toolbox used 


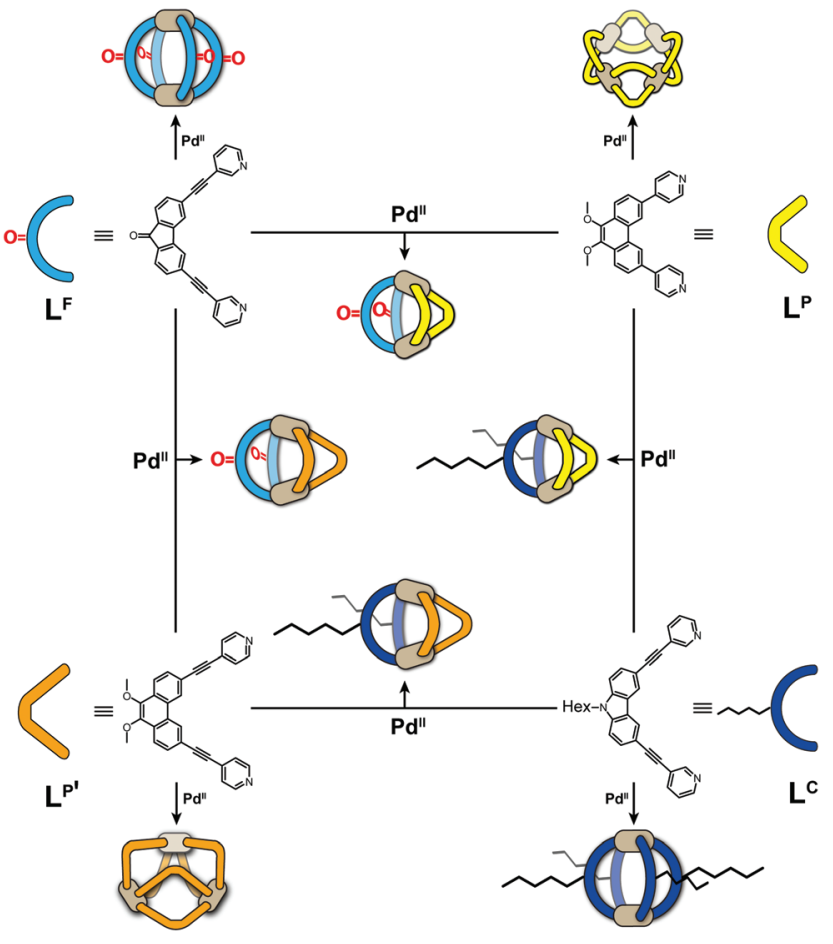

Fig. 1 Schematic overview of bis-monodentate ligands $L^{F}, L^{P}, L^{P^{\prime}}$ and $L^{C}$ reacting with $\mathrm{Pd}(॥)$ cations to form homoleptic cages or rings and - by pairwise combination - heteroleptic cages.

in supramolecular chemistry, ${ }^{9}$ in particular since user-friendly instruments have become commercially available. Among the different techniques that have been developed to unravel the size and shape of a molecule in the gas phase, expressed by its electric potential-driven mobility through a collision gas, trapped ion mobility spectrometry (TIMS) has been identified as an attractive method owing to the high resolution that can be achieved even without having to use metre-long drift tubes. ${ }^{10}$ We have recently applied this method for the discrimination of photo switchable cage isomers and their host-guest complexes ${ }^{11}$ the visualization of guest-induced expansion/contraction of helicene-based cages, ${ }^{12}$ and the analysis of G-quadruplex DNA folding states. ${ }^{13}$

Here, we show how ion mobility mass spectrometry can be used to clearly differentiate components in a mixture of up to ten different heteroleptic coordination cages, so close in size that DOSY NMR spectroscopy is not able to deliver an unambiguous differentiation (Fig. 1).

The herein described system is based on our recently developed approach of integrative self-sorting heteroleptic coordination cages from pairs of bis-monodentate ligands with wider and smaller donor angles, respectively. ${ }^{6}$ We chose to use two ligands with angles of $80^{\circ}$ based on a fluorenone-, respectively carbazole-backbone $\left(\mathbf{L}^{\mathrm{F}}\right.$ and $\left.\mathbf{L}^{\mathrm{C}}\right)$ and two phenanthrene-based ligands $\left(\mathbf{L}^{\mathbf{P}}\right.$ and $\left.\mathbf{L}^{\mathbf{P}^{\prime}}\right)$ which differ only in the length of their coordinating arms while both have donor angles of about $60^{\circ}$. While heteroleptic cage $\left[\operatorname{Pd}_{2} \mathbf{L}_{2}{ }_{2} \mathbf{L}_{2}{ }_{2}\right]$ has been previously reported by us, ${ }^{6}$ all other systems described herein are new.

\section{Results and discussion}

All heteroleptic cages were found to form selectively by adding a stoichiometric amount of $\mathrm{Pd}^{\mathrm{II}}$ cations to a $1: 1$ mixture of two matching banana-shaped ligands in DMSO or acetonitrile (details see ESI $\dagger$ ). Representative for all examined systems, the standard analytical data for the characterization of the $\mathbf{L}^{\mathrm{F}} / \mathbf{L}^{\mathbf{P}^{\prime}}$ system (i.e. showing the ${ }^{1} \mathrm{H}$ NMR traces of homoleptic $\left[\operatorname{Pd}_{2} \mathbf{L}_{4}^{\mathbf{F}}\right]^{4+}$, homoleptic $\left[\operatorname{Pd}_{3} \mathbf{L}^{\mathbf{P}^{\prime}}{ }_{6}\right]^{6+}$ and heteroleptic $\left[\operatorname{Pd}_{2} \mathbf{L}_{2}{ }_{2} \mathbf{L}^{\mathbf{P}^{\prime}}{ }_{2}\right]^{4+}$ plus the ESI mass spectrum of the latter one) is shown in Fig. 2.

Next, we examined the behaviour of ternary systems: with ligands $\mathbf{L}^{\mathbf{P}}$ and $\mathbf{L}^{\mathbf{P}^{\prime}}$ only differing by the lengths of their coordinating arms, we first prepared a system consisting of two equivalents of $\mathbf{L}^{\mathbf{F}}$ one equivalent of $\mathbf{L}^{\mathbf{P}}$ and one equivalent of $\mathbf{L}^{\mathbf{P}^{\prime}}$ (besides the stoichiometric amount of $\mathrm{Pd}^{\mathrm{II}}$ cations). ESI-MS analysis of the sample indicated the formation of three different species $\left[\operatorname{Pd}_{2} \mathbf{L}_{2}{ }_{2} \mathbf{L}^{\mathbf{P}}{ }_{x} \mathbf{L}^{\mathbf{P}^{\prime}}{ }_{y}\right]$ with $x+y=2 ; x=\{0-2\} ; y=$ $\{0-2\}$. The same situation was observed when repeating the experiment with $\mathbf{L}^{\mathbf{C}}$ instead of $\mathbf{L}^{\mathbf{F}}$, namely the formation of $\left[\operatorname{Pd}_{2} \mathbf{L}_{2}{ }_{2} \mathbf{L}_{x}{ }_{x} \mathbf{L}^{\mathbf{P}^{\prime}}\right]$ with $x+y=2 ; x=\{0-2\} ; y=\{0-2\}$. While this three-component mixture does not represent an entirely statistic outcome of all possible combinations of the three ligands (since $\mathbf{L}^{\mathbf{F}}$ or $\mathbf{L}^{\mathbf{C}}$, respectively, are always contributing two ligands to the structure), it certainly posed a quite sophisticated analytical problem due to the structural similarity of the contained species. As a result, we observed very complex ${ }^{1} \mathrm{H}$ NMR spectra for the ternary mixtures (see ESI $\dagger$ ) in which unambiguous signal assignment was not only hampered by an

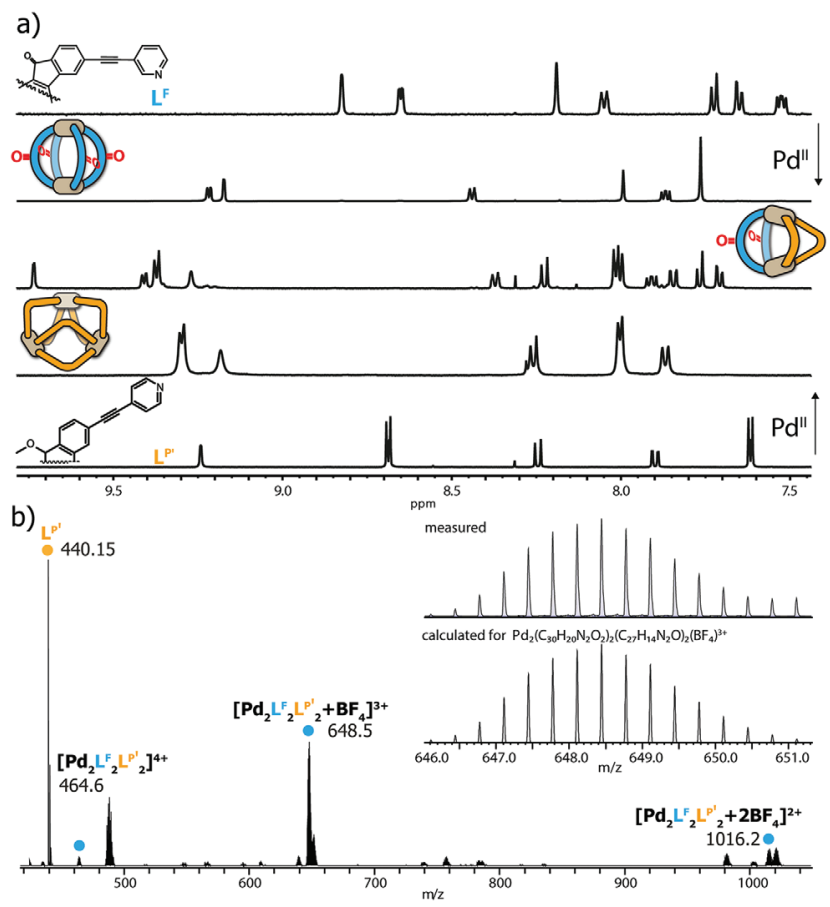

Fig. 2 (a) ${ }^{1} \mathrm{H}$ NMR spectra of $\mathrm{L}^{\mathrm{F}}$, homoleptic $\left[\mathrm{Pd}_{2} \mathrm{~L}_{4}\right]^{4+}$, heteroleptic $\left[\mathrm{Pd}_{2} \mathrm{~L}_{2} \mathrm{~L}^{\mathrm{P}^{\prime}}\right]^{4+}$, homoleptic $\left[\mathrm{Pd}_{3} \mathrm{~L}_{6} \mathrm{P}^{\prime}\right]^{6+}$ and $\mathrm{L}^{\mathrm{P}^{\prime}}$ (from top to bottom, $500 \mathrm{MHz}, 298 \mathrm{~K}, \mathrm{DMSO}-d_{6}$ ); (b) ESI mass spectrum of heteroleptic $\left[\mathrm{Pd}_{2} \mathrm{~L}_{2} \mathrm{~L}^{\mathrm{P}^{\prime}}\right]^{4+}$, including $\mathrm{BF}_{4}{ }^{-}$adducts. 
extensive peak overlap between the three components, but also by an additional symmetry-related signal splitting in compounds $\left[\operatorname{Pd}_{2} \mathbf{L}_{2}{ }_{2} \mathbf{L}_{1}{ }_{1} \mathbf{L}^{\mathbf{P}^{\prime}}{ }_{1}\right]$ and $\left[\operatorname{Pd}_{2} \mathbf{L}_{2}{ }_{2} \mathbf{L}_{1}{ }_{1} \mathbf{L}^{\mathbf{P}^{\prime}}{ }_{1}\right]$, respectively. We tried to distinguish the three heteroleptic cages, each, using standard ${ }^{1} \mathrm{H}$ DOSY NMR routines but also here, a reliable compound discrimination was thwarted by multiple signal overlaps and the substantial size similarity of the contained species. The recorded ${ }^{1} \mathrm{H}$ DOSY NMR spectra of both mixtures are shown in Fig. 3.

The DOSY spectra show, that for these minor size differences a clear differentiation of the cages from each other is almost impossible, not to mention obtaining reliable values for the respective diffusion coefficients.

Next, we subjected the mixtures to a Trapped Ion Mobility Spectrometry (TIMS) analysis on a Bruker timsTOF instrument which was indeed found to be capable of clearly discriminating the different cage species by their spatial dimension in the gas phase. We first analysed the two mixtures $\left[\operatorname{Pd}_{2} \mathbf{L}_{2}^{\mathbf{F}} \mathbf{L}_{x}{ }_{x} \mathbf{L}_{y}^{\mathbf{P}^{\prime}}\right]$ and $\left[\operatorname{Pd}_{2} \mathbf{L}_{2}{ }_{2} \mathbf{L}_{x}{ }^{\mathbf{P}} \mathbf{L}_{y}^{\mathbf{P}^{\prime}}\right](x+y=2 ; x=\{0-2\} ; y=\{0-2\})$ in separate measurements. In every measurement the $\left[\operatorname{Pd}_{2} \mathbf{L}_{2}{ }_{2} \mathbf{L}_{x}{ }_{x} \mathbf{L}^{\mathbf{P}^{\prime}}+\right.$ $\left.\mathrm{BF}_{4}\right]^{3+}$ respectively $\left[\operatorname{Pd}_{2} \mathbf{L}_{2}{ }_{2} \mathbf{L}^{\mathbf{P}_{x}} \mathbf{L}^{\mathrm{P}^{\prime}}{ }_{y}+\mathrm{BF}_{4}\right]^{3+}$ (Fig. 4a and b) species was chosen for the mobility comparison as it represented the most prominent peak in the ESI-MS spectrum (see ESI + ). For both systems, the TIMS measurement delivered baseline separated signals for the contained species with average peak-to-peak separations of $0.024 \mathrm{~V} \mathrm{~s} \mathrm{~cm}^{-2}$ and average peak widths of $0.029 \mathrm{~V} \mathrm{~s} \mathrm{~cm}^{-2}$ (baseline) and $0.014 \mathrm{~V} \mathrm{~s} \mathrm{~cm}^{-2}$ (FWHM).

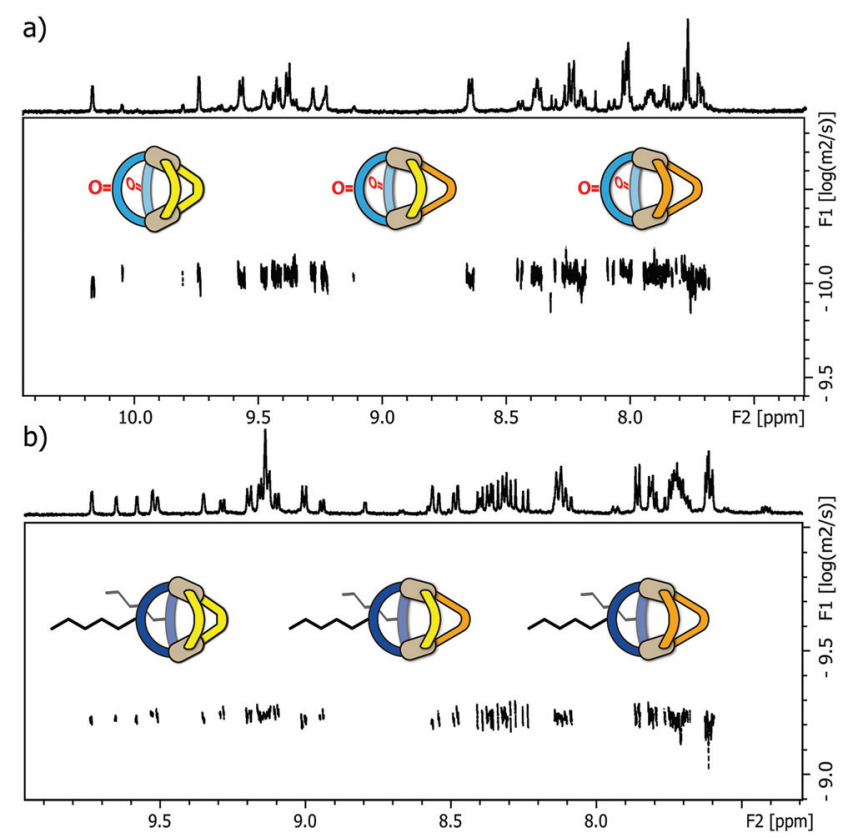

Fig. 3 (a) ${ }^{1} \mathrm{H}$ DOSY NMR spectrum of a mixture of heteroleptic cages

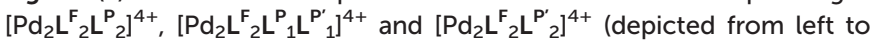
right, $500 \mathrm{MHz}, 298 \mathrm{~K}, \mathrm{DMSO}-d_{6}$ ); (b) ${ }^{1} \mathrm{H}$ DOSY NMR spectrum of a mixture of heteroleptic cages $\left[\mathrm{Pd}_{2} \mathrm{~L}_{2}{ }_{2} \mathrm{~L}^{\mathrm{P}}\right]^{4+},\left[\mathrm{Pd}_{2} \mathrm{~L}^{\mathrm{C}}{ }_{2} \mathrm{~L}^{\mathrm{P}} \mathrm{L}^{\mathrm{P}^{\prime}}{ }_{1}\right]^{4+}$ and $\left[\mathrm{Pd}_{2} \mathrm{~L}_{2} \mathrm{~L}^{\mathrm{P}_{2}}{ }_{2}\right]^{4+}$ (depicted from left to right, $500 \mathrm{MHz}, 298 \mathrm{~K}, \mathrm{CD}_{3} \mathrm{CN}$ ). In both cases, the depicted DOSY spectra do not allow a clear discrimination of the different species.

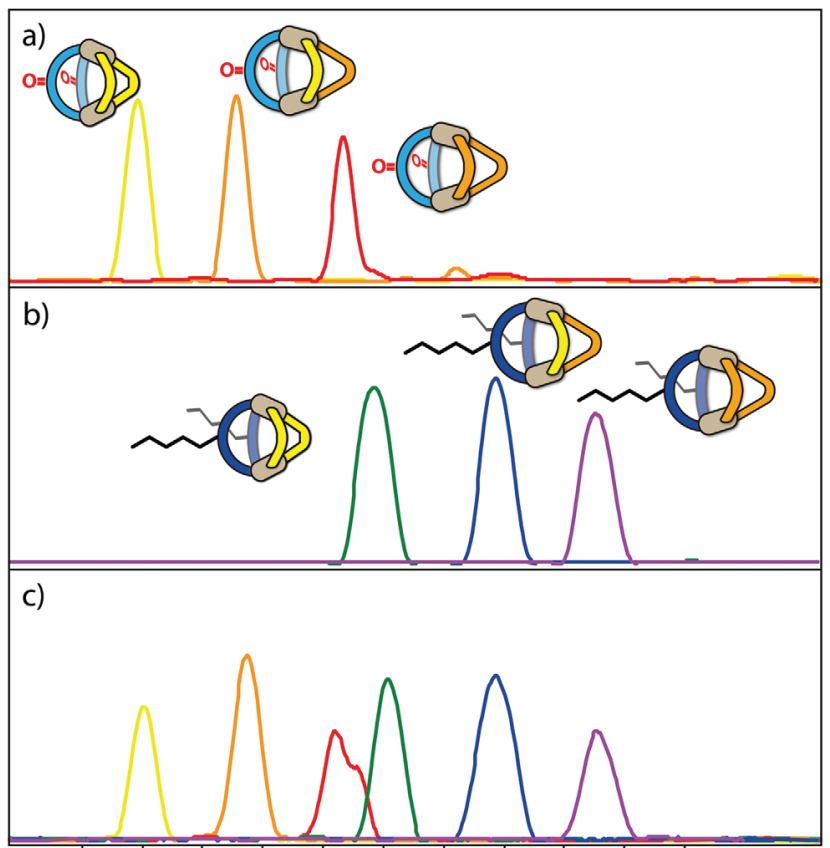

$\begin{array}{llllllllll}0.84 & 0.86 & 0.88 & 0.90 & 0.92 & 0.94 & 0.96 & 0.98 & 1.00 & \text { Mobility, } 1 / \mathrm{Ko}_{0}\left[\mathrm{~V} \cdot \mathrm{s} / \mathrm{cm}^{2}\right]\end{array}$

Fig. 4 Trapped lon Mobility (TIMS) derived mobilograms of (a) a mixture

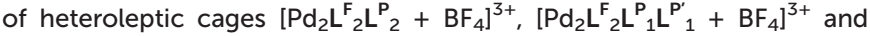
$\left[\mathrm{Pd}_{2} \mathrm{~L}_{2} \mathrm{~L}^{\mathrm{P}^{\prime}}{ }_{2}+\mathrm{BF}_{4}\right]^{3+}$; (b) a mixture of heteroleptic cages $\left[\mathrm{Pd}_{2} \mathrm{~L}_{2} \mathrm{~L}_{2} \mathrm{P}_{2}+\mathrm{BF}_{4}\right]^{3+}$,

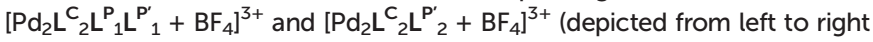
in the order of increasing collisional cross section) and (c) co-injection of both mixtures.

Being able to achieve a very clear differentiation within the two ternary systems, we decided to combine the two mixtures and tried to obtain separate ion mobility values for each of the six species from the resulting mixture (Fig. 4c). The measurement was performed right after combining the mixtures in order to avoid ligand shuffling between $\mathbf{L}^{\mathbf{F}}$ and $\mathbf{L}^{\mathbf{C}}$, both sharing almost the same donor geometry. While the absolute peak positions were found show minor deviations when comparing the mobilograms of the ternary mixtures (Fig. 4a and b) with the six-cage mixture (Fig. 4c), all six species can be unambiguously discriminated and assigned to their molecular structures.

TIMS analysis shows that the species containing the fluorenone-based ligand $\mathbf{L}^{\mathbf{F}}$ have an overall lower ion mobility, and thus a smaller collisional cross section (CCS), serving as an isotropic measure for comparing cage dimensions, ${ }^{9}$ than the species with the carbazole-based ligand $\mathbf{L}^{\mathrm{C}}$, even though they share a very similar backbone structure (all values refer to the results shown in Fig. 4 a and b; details see ESI $\dagger$ ). The effect can thus be ascribed to the hexyl-chains attached to the carbazolebackbone. The significant difference in ion mobility suggests, that the chains do not seem to completely fold back to the backbone in the gas phase but instead significantly contribute to the spatial extent of the $\left[\mathrm{Pd}_{2} \mathbf{L}_{2}{ }_{2} \mathbf{L}_{x}{ }_{x} \mathbf{L}^{\mathbf{P}^{\prime}}{ }_{y}+\mathrm{BF}_{4}\right]^{3+}$ species. The same effect can also be seen when comparing the ${ }^{1} \mathrm{H}$ DOSY NMR spectra of the two mixtures where the $\left[\operatorname{Pd}_{2} \mathbf{L}_{2}{ }_{2} \mathbf{L}_{x}^{\mathbf{P}} \mathbf{L}^{\mathbf{P}^{\prime}}{ }_{y}\right]$ species have a larger diffusion coefficient than the 
$\left[\mathrm{Pd}_{2} \mathbf{L}_{2}{ }_{2} \mathbf{L}_{x}{ }^{\mathbf{P}} \mathbf{L}^{\mathbf{P}^{\prime}}\right]$ species $(x+y=2 ; x=\{0-2\} ; y=\{0-2\})$ corresponding to an overall smaller hydrodynamic radius in comparison to the latter (Fig. 3). It should be noted, however, that care has to be taken when comparing the behaviour of the alkyl chains in the gas and solution phase, since London dispersion effects will dominate the interaction of the chains with the cage's core in the former case while chain-solvent interactions will be more decisive in the latter case.

Remarkably, ion mobility analysis - in tandem with mass spectrometry - allows the detection of quite small size differences. For example, compounds $\left[\mathrm{Pd}_{2} \mathbf{L}_{2} \mathbf{L}^{\mathbf{P}_{2}}{ }_{2}+\mathrm{BF}_{4}\right]^{3+}$ and $\left[\mathrm{Pd}_{2} \mathbf{L}_{2}{ }_{2} \mathbf{L}_{2}{ }_{2}+\mathrm{BF}_{4}\right]^{3+}$ show only a small mobility difference (Fig. 4c). Nevertheless, ion mobility mass spectrometry allows their clear differentiation in the six-cage mixture for two reasons: (a) their different mass allows the superposition of mass-selected mobilograms even when both species are parts of the same sample and (b) the high resolution of the TIMS analyser yields a clear separation of the peak maxima. Interestingly, two mobilities can be assigned to the $\mathrm{m} / \mathrm{z}$ value corresponding to $\left[\mathrm{Pd}_{2} \mathbf{L}_{2}{ }_{2} \mathbf{L}^{\mathrm{P}^{\prime}}{ }_{2}+\mathrm{BF}_{4}\right]^{3+}$ (clearly visible as doublepeak in Fig. $4 \mathrm{a}$ and in the measurement of the clean heteroleptic cage depicted in the ESI $\dagger$ ). As possible explanation we suggest the existence of two energetically locked cage conformations under the given gas-phase conditions. Arguing with a tentative trans-arrangement of the contained ligands, however, can be ruled out based on strain calculations comparing cisand trans-isomers of $\left[\operatorname{Pd}_{2} \mathbf{L}_{2}{ }_{2} \mathbf{L}_{2}^{\mathbf{P}}\right]^{6}$

Encouraged by these results, we prepared a sample by mixing one equivalent of every ligand (4 eq. in total) followed by the addition of two equivalents of $\mathrm{Pd}^{\mathrm{II}}$ cations. Where we prevented $\mathbf{L}^{\mathrm{C}}$ - and $\mathbf{L}^{\mathrm{F}}$-containing species from mixing in the previous experiment, we were now aiming for complete ligand shuffling. Due to the almost identical shape of $\mathbf{L}^{\mathrm{C}}$ and $\mathbf{L}^{\mathrm{F}}$, we expected them to appear in the formed cages in a statistical manner. The distinct shape complementarity between $\mathbf{L}$ and $\mathbf{L}^{\prime}$, however, only allows for the formation of $\operatorname{Pd}_{2} \mathbf{L}_{2} \mathbf{L}_{2}^{\prime}$ species in which $\mathbf{L}$ must be either $\mathbf{L}^{\mathbf{C}}$ or $\mathbf{L}^{\mathbf{F}}$ and $\mathbf{L}^{\prime}$ must be $\mathbf{L}^{\mathbf{P}}$ or $\mathbf{L}^{\mathbf{P}^{\prime}}$. This restriction was expected to lead to the formation of ten distinct coordination cages of which two are isomers, carrying all four ligands in a cis $\left(\mathbf{L}^{\mathbf{F}}\right.$ next to $\left.\mathbf{L}^{\mathbf{P}}\right)$ or trans $\left(\mathbf{L}^{\mathbf{F}}\right.$ opposite to $\mathbf{L}^{\mathbf{P}}$ ) arrangement. As it has been stated before, differentiation of most species can be made based on their mass alone. This, however, does not apply to the two isomers which do not only have the exact same mass but also a very similar shape and size. The mobilogram obtained from the TIMS measurement of the ten cage mixture is shown in Fig. 5.

The measurement shows that distinguishing all ten cages by high resolution trapped ion mobility is indeed possible, including the isomeric cis and trans $-\left[\mathrm{Pd}_{2} \mathbf{L}^{\mathbf{C}} \mathbf{L}^{\mathbf{F}} \mathbf{L}^{\mathbf{P}} \mathbf{L}^{\mathbf{P}^{\prime}}+\mathrm{BF}_{4}\right]^{3+}$ species with an $\mathrm{m} / \mathrm{z}$ value of 656.15 (Fig. $5 \mathrm{a}-\mathrm{c}$ ). It should be noted that these isomers only differ by $4.3 \AA^{2}(0.8 \%$ with an achieved resolution of up to $1601 / K_{0}$ ) in their collisional cross sections.

In order to illustrate and theoretically reproduce the structural differences between all examined cage derivatives, we prepared molecular models shown in Fig. 6 by geometry optimization on a semi-empiric (PM6) level of theory using the

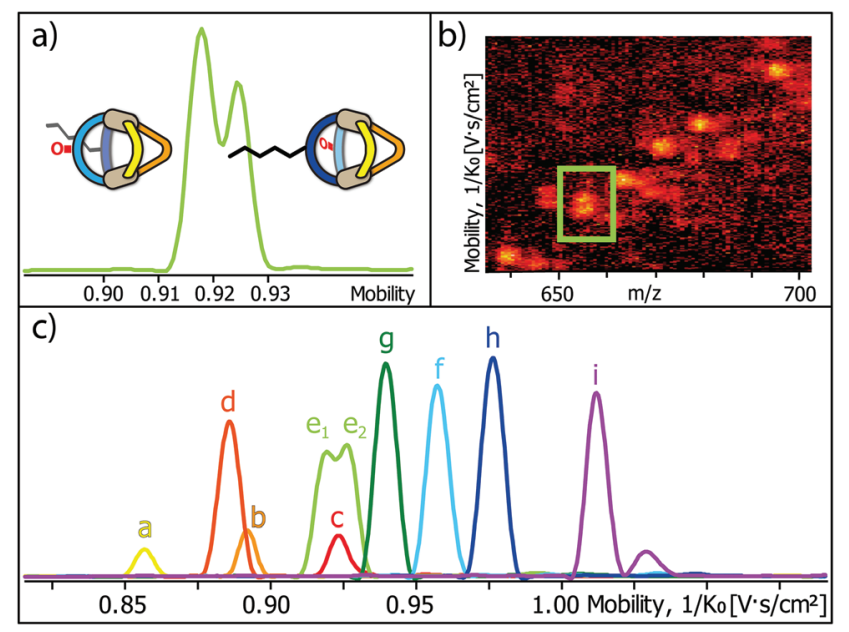

Fig. 5 (a) High resolution TIMS mobilogram allowing the discrimination

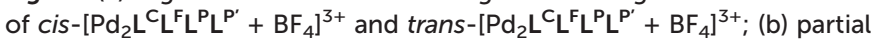
heat map and (c) full mobilogram of the simultaneous ion mobility measurement of all ten coordination cages; assignments a-i correspond to cages shown in Fig. 6. a)

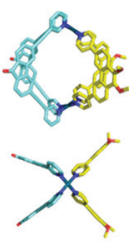

d)

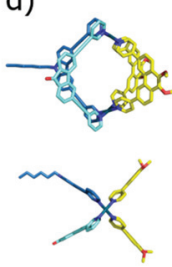

g)

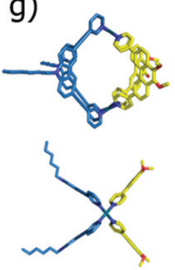

b)

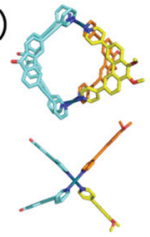

$\left.\mathrm{e}_{1}\right)$

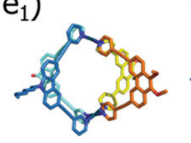

$\left.\mathrm{e}_{2}\right)$
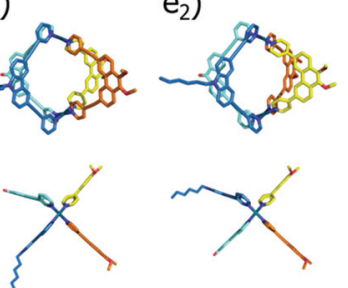

h)

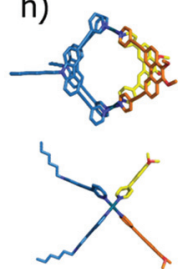

c)

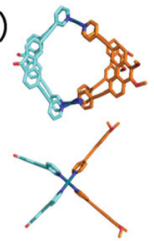

f)

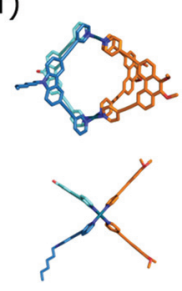

i)

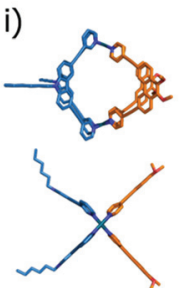

Fig. 6 Geometry optimized structures of (a) $\left[\mathrm{Pd}_{2} \mathrm{~L}_{2} \mathrm{~L}^{\mathrm{P}}{ }_{2}\right]^{4+}$; (b)

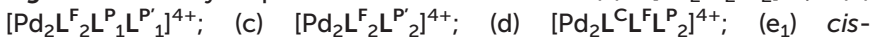
$\left[\mathrm{Pd}_{2} \mathrm{~L}^{\mathrm{C}} \mathrm{L}^{\mathrm{F}} \mathrm{L}^{\mathrm{P}}{ }_{1} \mathrm{~L}^{\mathrm{P}^{\prime}}{ }_{1}\right]^{4+} ;\left(\mathrm{e}_{2}\right)$ trans- $\left[\mathrm{Pd}_{2} \mathrm{~L}^{\mathrm{C}} \mathrm{L}^{\mathrm{F}} \mathrm{L}_{1}{ }_{1} \mathrm{~L}^{\mathrm{P}^{\prime}}{ }_{1}\right]^{4+} ;$ (f) $\left[\mathrm{Pd}_{2} \mathrm{~L}^{\mathrm{C}} \mathrm{L}^{\mathrm{F}} \mathrm{P}^{\prime}{ }_{2}\right]^{4+} ;(\mathrm{g})$

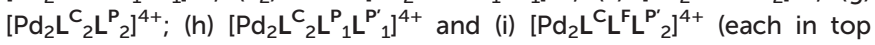
and side view).

Spartan '14 software'. ${ }^{14}$ While the models show that the height of the cages (in direction of the Pd-Pd axis) remains almost the same, the average diameters differ significantly.

To further validate the results from the ion mobility measurements and to yield an assignment for the isomeric cage species to the corresponding mobilities, we chose two 
in silico approaches for calculating theoretical CCS (tCCS) values via the programs $\mathrm{IMoS}^{15}$ using the 'projected area method' which averages the projected 2D area according to van der Waals radii, and a modified version of MOBCAL, ${ }^{16}$ using a 'trajectory method' which simulates the interaction of the analyte with the collision gas molecules. As the factor for compensating the neglect of momentum transfer and longrange potential interactions ${ }^{17}$ for the 'projected area method' a value $\xi=1.2$ was chosen. In preparation for these calculations we used a new, efficient method for geometry optimization on a semi-empiric level, namely the GFN-xTB method developed by Grimme et al. ${ }^{18}$ As an alternative to MOBCAL and IMoS, another software based on the trajectory method, collidoscope ${ }^{19}$ was used but found to perform worse to yield reasonable results and correct trends for this system (see ESI $\dagger$ ). Table 1 compares the experimental with the theoretical values.

Theoretical values derived from the 'projected area method' and the 'trajectory method' were both found to fit the experimentally observed values quite well (Table 1; Fig. 7). While MOBCAL shows an average overestimation of $33.2 \AA^{2}(6 \%)$, IMoS gives a slight underestimation of $15.2 \AA^{2}(2 \%)$. Most pleasingly, both calculation methods confirm the order in the

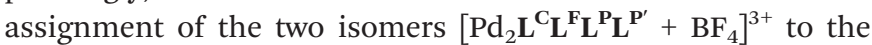
observed peaks in the mobilogram, although these structures

Table 1 Comparison of collisional cross section data (CCS). For each of the ten examined species (a-i, according to Fig. 6) experimentally determined values (eCCS) and values calculated using IMoS (projected area; $\mathrm{tCCS}^{\mathrm{PA}}$ ) and MOBCAL (trajectory method; $\mathrm{tCCS}^{\mathrm{M}}$ ) are given (theoretical values refer to $\left[\text { cage }+\mathrm{BF}_{4}\right]^{3+}$ species, details see $\mathrm{ESI}$ )

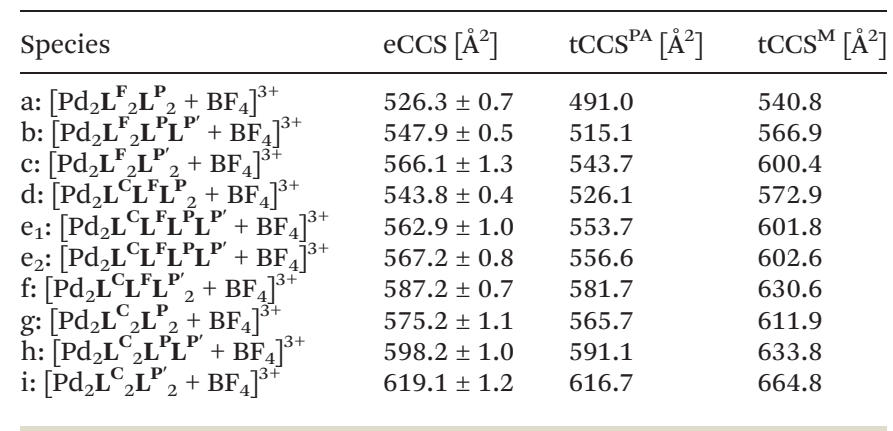

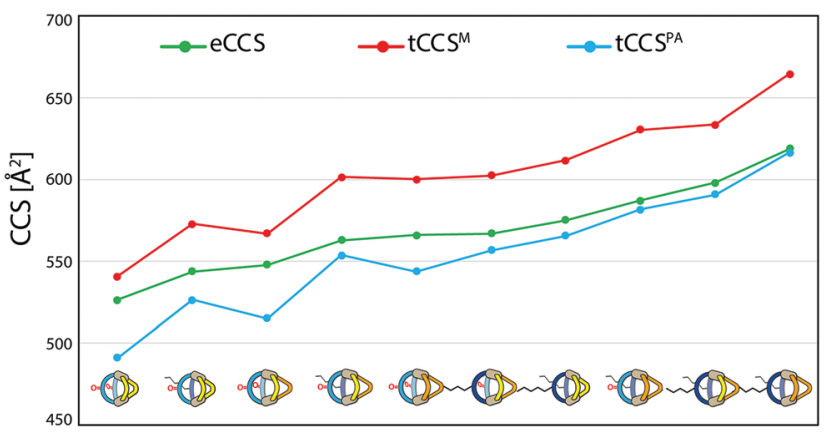

Fig. 7 Graphical representation of the measured CCS values (eCCS, green) compared to the calculated CCS values using MOBCAL $\left(\mathrm{tCCS}^{\mathrm{M}}\right.$, red) and IMOS (tCCS ${ }^{\mathrm{PA}}$, blue). are extremely close in structure and size. We assume that remaining deviations between experimental and calculated values are in part caused by simplifying the analysis to single, geometry-optimized conformers. Consequently, our current efforts focus on systematic investigations of Boltzmannweighted conformational distributions for structurally flexible species.

\section{Conclusions}

With supramolecular self-assemblies becoming more and more complex over the past years, both in terms of individual structures as well as complex system composition, researchers in the field are in need of new powerful analytical methods. The herein introduced system consists of ten heteroleptic cages, two of them being isomers, very close in size, that standard DOSY NMR analytics could not resolve. Trapped ion mobility mass spectrometry (TIMS), however, proved to be a valuable tool for analysing such a complex system. We were not only able to differentiate the cage species from a mixture of three different heteroleptic cages but could furthermore show that discrimination is even possible from a six- and even ten-component system while the cages feature differences in their radii of less than $0.1 \AA$. Furthermore, the theoretical calculation of collisional cross sections allowed us to reproduce the experimentally found size trends and unambiguously assign the signals of two isomeric metallo-supramolecular assemblies, extremely close in structure and size.

\section{Conflicts of interest}

There are no conflicts to declare.

\section{Acknowledgements}

We thank the Deutsche Forschungsgemeinschaft (CL489/2-2, CL489/3-2 [SPP1807] and GRK2376 "Confinement-controlled Chemistry" - project number 331085229) and the European Research Council, ERC Consolidator grant 683083 (RAMSES) for financial support. We thank Dr Julian Holstein for help with the determination of theoretical CCS data. We thank Dr Witold Bloch for ligand $\mathbf{L}^{\mathbf{P}}$, and Prof. Dr Wolf Hiller and team for support with NMR measurements.

\section{Notes and references}

1 (a) B. H. Northrop, Y.-R. Zheng, K.-W. Chi and P. J. Stang, Acc. Chem. Res., 2009, 42, 1554; (b) R. Chakrabarty, P. S. Mukherjee and P. J. Stang, Chem. Rev., 2011, 111, 6810; (c) M. M. J. Smulders, I. A. Riddell, C. Browne and J. R. Nitschke, Chem. Soc. Rev., 2013, 42, 1728.

2 G. H. Clever and P. M. Punt, Acc. Chem. Res., 2017, 50, 2233. 
3 (a) S. Saha, I. Regeni and G. H. Clever, Coord. Chem. Rev., 2018, 374, 1; (b) R. Custelcean, Chem. Soc. Rev., 2014, 43, 1813; (c) L. R. Holloway, P. M. Bogie and R. J. Hooley, Dalton Trans., 2017, 46, 14719.

4 (a) W. M. Bloch and G. H. Clever, Chem. Commun., 2017, 53, 8506; (b) S. Mukherjee and P. S. Mukherjee, Chem. Commun., 2014, 50, 2239; (c) S. Pullen and G. H. Clever, Acc. Chem. Res., 2018, 51, 3052; (d) D. Preston, J. E. Barnsley, K. C. Gordon and J. D. Crowley, J. Am. Chem. Soc., 2016, 138, 10578; (e) B. Mondal, K. Acharyya, P. Howlader and P. S. Mukherjee, J. Am. Chem. Soc., 2016, 138, 1709; $(f)$ L. Zhang, Y.-J. Lin, Z.-H. Li and G.-X. Jin, J. Am. Chem. Soc., 2015, 137, 13670; (g) Q.-F. Sun, S. Sato and M. Fujita, Angew. Chem., Int. Ed., 2014, 53, 13510; (h) M. Yamanaka, Y. Yamada, Y. Sei, K. Yamaguchi and K. Kobayashi, J. Am. Chem. Soc., 2006, 128, 1531.

5 R. Zhu, W. M. Bloch, J. J. Holstein, S. Mandal, L. V. Schäfer and G. H. Clever, Chem. - Eur. J., 2018, 24, 12976.

6 (a) W. M. Bloch, Y. Abe, J. J. Holstein, C. M. Wandtke, B. Dittrich and G. H. Clever, J. Am. Chem. Soc., 2016, 138, 13750; (b) W. M. Bloch, J. J. Holstein, W. Hiller and G. H. Clever, Angew. Chem., Int. Ed., 2017, 56, 8285; (c) S. Saha, B. Holzapfel, Y.-T. Chen, K. Terlinden, P. Lill, C. Gatsogiannis, H. Rehage and G. H. Clever, J. Am. Chem. Soc., 2018, 140, 17384.

7 (a) L. Avram and Y. Cohen, Chem. Soc. Rev., 2015, 44, 586; (b) S. V. Kharlamov and S. K. Latypov, Russ. Chem. Rev., 2010, 79, 635; (c) A. Pastor and E. Martinez-Viviente, Coord. Chem. Rev., 2008, 252, 2314.

8 (a) C. A. Schalley, Mass Spectrom. Rev., 2001, 20, 253; (b) Analytical Methods in Supramolecular Chemistry, ed. C. A. Schalley, WILEY-VCH, Weinheim, Germany, 2007; (c) Z. Qi, T. Heinrich, S. Moorthy and C. A. Schalley, Chem. Soc. Rev., 2015, 44, 515.

9 (a) E. Kalenius, M. Groessl and K. Rissanen, Nat. Rev. Chem., 2019, 3, 4; (b) M. Wang, C. Wang, X.-Q. Hao, X. Li, T.-J. Vaughn, Y.-Y. Zhang, Y. Yu, Z.-Y. Li, M.-P. Song, H.-B. Yang and X. Li, J. Am. Chem. Soc., 2014, 136, 10499; (c) C. A. Scarff, J. R. Snelling, M. M. Knust, C. L. Wilkins and J. H. Scrivens, J. Am. Chem. Soc., 2012, 134(22), 9193; (d) E. R. Brocker, S. E. Anderson, B. H. Northrop, P. J. Stang and M. T. Bowers, J. Am. Chem. Soc., 2010, 132(38), 13486; (e) Y.-T. Chan, X. Li, J. Yu, G. A. Carri, C. N. Moorefield, G. R. Newkome and C. Wesdemiotis, J. Am. Chem. Soc., 2011, 133(31), 11967; (f) J. Ujma, M. De Cecco, O. Chepelin, H. Levene, C. Moffat, S.-J. Pike, P.-J. Lusby and P.-E. Barran, Chem. Commun., 2012, 48, 4423; (g) P. J. Robbins, A. J. Surman, J. Thiel, D.-L. Long and L. Cronin, Chem. Commun., 2013, 49, 1909; (h) P. Bonakdarzadeh, F. Topic, E. Kalenius, S. Bhowmik, S. Sato, M. Groessl, R. Knochenmuss and K. Rissanen, Inorg. Chem., 2015, 54, 6055; (i) J. Thiel, D. Yang, M. H. Rosnes, X. Liu, C. Yvon, S. E. Kelly, Y.-F. Song, D.-L. Long and L. Cronin, Angew. Chem., Int. Ed., 2011, 50, 8871; (j) X. Li, Y.-T. Chan, M. Casiano-Maldonado, J. Yu, G. A. Carri, G. R. Newkome and C. Wesdemiotis, Anal. Chem., 2011, 83, 6667; (k) C. Lapthorn, F. Pullen and B. Z. Chowdhry, Mass Spectrom. Rev., 2013, 32, 43; (l) J. M. Ludlow, M. Tominaga, Y. Chujo, A. Schultz, X. Lu, T. Xie, K. Guo, C. N. Moorefield, C. Wesdemiotis and G. R. Newkome, Dalton Trans., 2014, 43, 9604; (m) C. Wang, X.-Q. Hao, M. Wang, C. Guo, B. Xu, E. N. Tan, Y.-Y. Zhang, Y. Yu, Z.-Y. Li, H.-B. Yang, M.-P. Song and X. Li, Chem. Sci., 2014, 5, 1221; (n) N. J. Rijs, T. Weiske, M. Schlangen and H. Schwarz, Anal. Chem., 2015, 87, 9769; (o) F. Lanucara, S. W. Holman, C. J. Gray and C. E. Eyers, Nat. Chem., 2014, 6, 281; (p) F. J. Rizzuto, M. Kiefer and J. R. Nitschke, Chem. Sci., 2018, 9, 1925; (q) K. Caprice, M. Pupier, A. Kruve, C. A. Schalley and F. B. L. Cougnon, Chem. Sci., 2018, 9, 1317.

10 (a) J.-F. Greisch, J. Chmela, M. Harding, D. Wunderlich, B. Schäfer, M. Ruben, W. Klopper, D. Schooss and M. M. Kappes, Phys. Chem. Chem. Phys., 2017, 19, 6105; (b) J.-F. Greisch, P. Weis, K. Brendle, M. M. Kappes, J. R. N. Haler, J. Far, E. De Pauw, C. Albers, S. Bay, T. Wurm, M. Rudolph, J. Schulmeister and A. S. K. Hashmi, Organometallics, 2018, 37, 1493.

11 R. Li, J. J. Holstein, W. G. Hiller, J. Andréasson and G. H. Clever, J. Am. Chem. Soc., 2019, 141, 2097.

12 T. R. Schulte, J. J. Holstein and G. H. Clever, Angew. Chem., Int. Ed., 2019, 58, 5526.

13 P. M. Punt and G. H. Clever, Chem. Sci., 2019, 10, 2513.

14 Spartan '14 Version 1.1.8, Wavefunction, Inc., Irvine, CA, 2014.

15 C. Larriba and C. J. Hogan, J. Phys. Chem., 2013, 19, 3887.

16 (a) M. F. Mesleh, J. M. Hunter, A. A. Shvartsburg, G. C. Schatz and M. F. Jarrold, J. Phys. Chem., 1996, 100, 16082; (b) I. Campuzano, M. F. Bush, C. V. Robinson, C. Beaumont, K. Richardson, H. Kim and H. I. Kim, Anal. Chem., 2012, 84, 1026.

17 C. Larriba and C. J. Hogan, J. Comput. Phys., 2013, 251, 344. 18 S. Grimme, C. Bannwarth and P. Shushkov, J. Chem. Theory Comput., 2017, 13, 1989.

19 S. A. Ewing, M. T. Donor, J. W. Wilson and J. S. Prell, J. Am. Soc. Mass. Spectrom., 2017, 28, 587. 